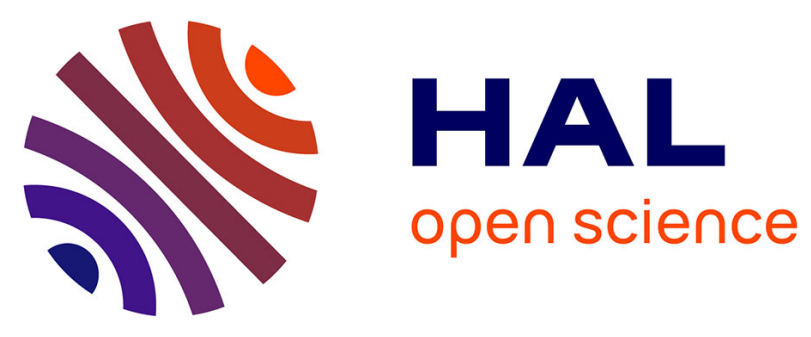

\title{
Does an aberrant right hepatic artery really influence the short- and long-term results of a pancreaticoduodenectomy for malignant disease? A matched case-controlled study.
}

Laurent Sulpice, Michel Rayar, Cyrielle Paquet, Damien Bergeat, Aude

Merdrignac, Diane Cunin, B. Meunier, Karim Boudjema

\section{To cite this version:}

Laurent Sulpice, Michel Rayar, Cyrielle Paquet, Damien Bergeat, Aude Merdrignac, et al.. Does an aberrant right hepatic artery really influence the short- and long-term results of a pancreaticoduodenectomy for malignant disease? A matched case-controlled study.: Aberrant right hepatic artery during pancreaticoduodenectomy. Journal of Surgical Research, 2013, 185 (2), pp.620-5. 10.1016/j.jss.2013.07.015 . inserm-00864265

\section{HAL Id: inserm-00864265 https://www.hal.inserm.fr/inserm-00864265}

Submitted on 20 Sep 2013

HAL is a multi-disciplinary open access archive for the deposit and dissemination of scientific research documents, whether they are published or not. The documents may come from teaching and research institutions in France or abroad, or from public or private research centers.
L'archive ouverte pluridisciplinaire HAL, est destinée au dépôt et à la diffusion de documents scientifiques de niveau recherche, publiés ou non, émanant des établissements d'enseignement et de recherche français ou étrangers, des laboratoires publics ou privés. 
Clean version

Does an aberrant right hepatic artery really influence the short- and long-term results of a pancreaticoduodenectomy for malignant disease? A matched case-controlled study

Sulpice L, MD ${ }^{1,2}$, Rayar $M, M D^{1}$, Paquet $C, M D^{1}$, Bergeat $D, M D^{1}$, Merdrignac $A, M D^{1}$, Cunin $\mathrm{D}, \mathrm{MD}^{1}$, Meunier $\mathrm{B}, \mathrm{MD}^{1}$, and Boudjema $\mathrm{K}, \mathrm{MD}^{1,2}$

${ }^{1}$ Service de Chirurgie Hépatobiliaire et Digestive, Hôpital Pontchaillou, Centre Hospitalier Universitaire, Université de Rennes 1, Rennes, France

2 INSERM, UMR991. Foie, métabolisme et cancer. Université de Rennes1, Rennes, France This work has been presented as an oral communication to EHPBA, Belgrade, June 2013, Running title: Aberrant right hepatic artery during pancreaticoduodenectomy

Correspondence:

Doctor Laurent Sulpice

Service de Chirurgie Hépatobiliaire et Digestive, Hôpital Pontchaillou, Centre Hospitalier Universitaire, Université de Rennes 1, Rennes, France

Telephone: + 33299284265 Fax: + 33299284129

Email: laurent.sulpice@chu-rennes.fr

Keywords: Aberrant right hepatic artery, pancreaticoduodenectomy, outcomes, survival

Conflicts of interest: The authors have no conflicts of interest to declare.

Funding: The study received no external support.

Category of submission: Original article 


\section{Author contributions}

LS conceived and designed the study, undertook the analysis and interpretation of data, and wrote and finalized the manuscript. MR collected data and provided the statistical analysis. CP collected and analyzed the data. DB collected and analyzed the data. AM helped for revised manuscript. DC collected and analyzed the data. BM revised the manuscript. KB revised the manuscript and gave the final approval for publication. 


\section{ABSTRACT}

Background: An aberrant right hepatic artery ( $\mathrm{ARHA})$ is a common anatomical variation. The risk associated with ARHA during pancreaticoduodenectomy (PD) continues to be debated. The aim of this study was to compare the clinical outcomes and survival after PD with ARHA against a matched cohort of patients without AHRA.

Methods: PD with an ARHA performed between January 2000 and September 2009 were retrospectively analyzed. Patients with an AHRA (group 1) were matched (1:2) to patients without an ARHA (group 2) according to gender, age, BMI, type of tumor and lymph nodes status. Peri- and postoperative outcomes were compared between the 2 groups. Overall (OS) and disease free (DFS) survival were estimated by Kaplan-Meier method and compared with Log-rank test.

Results: A total of 29 patients (group 1) and 55 patients (group 2) were compared. In group 1, an AHRA entered the tumor in 6 cases (20.7\%), was sacrificed in 4 cases, and repaired in 2 cases. There was no difference regarding the rate of intraoperative and postoperative variables between the 2 groups. The oncological clearance $(p=0.731)$ and survival (OS, $p=0.843$; DFS, $p=0.832$ ) were also similar.

Conclusions: Our study showed that the presence of an AHRA during PD was not associated with worse postoperative outcomes or survival. 


\section{INTRODUCTION}

Pancreaticoduodenectomy (PD) remains the only curative treatment currently available for malignant diseases of the pancreatic head. Improvements in operative techniques and postoperative care have significantly decreased the mortality after PD within the last two decades in high-volume centers $(1 ; 2)$. The morbidity rates after PD remain high, reaching $30-50 \%(3 ; 4)$. Morbidity is partly related to peri- and postoperative hemorrhage $(5 ; 6)$, which may be due to the highly variable arterial anatomy, particularly the anatomy of the hepatic artery (HA). These variations were fully described by Michels (7) from 200 autopsies and confirmed by Hiats et al. on 1000 liver donors (8). Among these anatomical variations, the Achilles heel during PD is the presence of an aberrant right hepatic artery (ARHA), including a replaced and accessory right hepatic artery, which is present in 10 to $18 \%$ of the population $(8 ; 9)$. ARHAs arise from the superior mesenteric artery (SMA), cross behind or through the head of the pancreas before skirting laterally or behind the portal vein, and finally penetrate the hepaticoduodenal ligament postero-laterally to the bile duct. It is imperative to look for the presence of an ARHA pre- and perioperatively to avoid its injury. When an AHRA is present, the challenge in peripancreatic malignant disease is the balance between its preservation and the need to achieve oncological clearance, which represents the only chance for prolonged survival. To date, few studies have evaluated the impact of the presence of an ARHA during PD in this difficult situation (10-13). These studies focused more on the management of ARHAs than on the impact that ARHAs have on recurrence and survival.

The aim of this study was to retrospectively analyze the outcomes and oncological results of PD in patients with ARHA when performed in a tertiary referral center. Particular attention was focused on the risk of an incomplete resection associated with the presence of ARHA. 


\section{METHODS}

\section{Patients}

The study population included all of the consecutive PD for malignant disease that were performed at a single tertiary referral center between January 2000 and September 2009. The clinical data were retrospectively analyzed after retrieval from a prospectively collected PD database. Institutional Review Board approval was obtained for this study.

The collected data included age, sex, body mass index (BMI), tumor type, lymph node status, duration of surgery, venous or arterial resection and reconstruction, concomitant abdominal surgery, and transfusion needs. The postoperative complications of pancreatic fistula rates, classified into three groups ( $A, B$, and $C)$ according to the International Study Group of Pancreatic Fistula (ISGPF) criteria(14), and delayed gastric emptying (DGE) graded according to International Study Group of Pancreatic Surgery (ISPGS) criteria (15) were assessed. In this series, only pancreatic fistulas of grades B and C were considered because the nasogastric tube (NGT) was systematically left in place for 5 days. We also assessed postpancreatectomy hemorrhage, including intra- and extra-luminal bleeding according to the ISGPS definition; biliary fistula, defined as the presence of bile in the drainage fluid; and systemic infections, defined as the association of infectious signs with the need for systemic antibiotics. Perioperative mortality was defined as death during the initial hospital stay or within 30 days of surgery if the patient was discharged.

\section{Surgery and Follow-up protocol}

All patients underwent PD with an antrectomy and Child reconstruction. All of the procedures were performed by senior pancreatic surgeons, and a superior mesenteric artery first approach was performed systematically after 2006. In the last years of the study period, the decision to sacrifice or repair was based on the caliber of the artery, the presence or absence of a back flow from the distal part of the artery and the results of intraoperative liver 
Doppler ultrasonography. Adjuvant chemotherapy was systematically administrated for patient with pancreatic adenocarcinoma with gemcitabine, whereas patients with distal bile duct cholangiocarninoma had not. Regarding malignant ampulloma, only patients with positive lymph nodes involvement benefited from chemotherapy by FOLFOX or LV5FU2 regiments. After the resection, all patients were followed up every three months. A CT scan was performed every 3 months during the first 2 years and every six months thereafter. Follow-up data were obtained through routine clinic visits or through personal contact. The end of follow-up was set at August 1, 2012, or at the time of death.

\section{Statistical analysis}

To analyze the impact of the presence of ARHA during PD, the patients with an ARHA were identified by reviewing surgical reports (group 1) and were matched one-to-two with patients without an ARHA (group 2) from the PD database. The match was obtained according to age, sex, BMI, tumor type and lymph node status.

The quantitative variables were expressed as the mean \pm standard deviation (SD) or the median value and compared using Student's t-test or Wilcoxon test as appropriate. The qualitative variables were expressed as the mean \pm SD and percentage and compared by Chi-squared or Fisher's exact tests, as appropriate. The cumulative survival rates were estimated by the Kaplan-Meier method. The overall survival (OS) was calculated from the day of surgery to the date of death or the end of follow-up. Disease-free survival (DFS) was calculated using the date of death or recurrence as the time of the terminal event. The survival curves were compared by a log-rank test. A $p$ value of $<0.05$ was considered statistically significant. R statistical software, version 2.15 .1 (http://www.r-project.org/), was used. 


\section{RESULTS}

\section{Demographic data and matched group}

During the study period, 213 patients underwent PD with curative intent for malignant disease. Among these 213 patients, 29 (13.6\%) had an ARHA (group 1), including 18 (62\%) cases and $11(38 \%)$ cases of type 6 (accessory RHA) and type 3 (replaced RHA) of the Michels classification, respectively They were matched 1:2, and only 55 patients (group 2) of the 58 planned matches were found according to the matching criteria. The demographic data and histopathology features of the two groups are reported in table 1 and show great matching correlation.

In group 1, AHRAs were diagnosed preoperatively by CT scan or angio-MRI (Figure 1A and 1B) or during surgery in $20(69 \%)$ and $9(31 \%)$ cases, respectively. No patient received preoperative embolization of the ARHA to prevent any possible complications related to intraoperative sacrifice. Among the 29 cases of ARHA, 23 (79.3\%) were dissected free and preserved (figure 1C), whereas 6 crossed into the tumor $(20.7 \%)$ and were either sacrificed in 4 cases or reconstructed in 2 cases (figure 2).

\section{Perioperative data and outcomes}

Peri- and postoperative outcomes of the two groups are provided in table 2. There were no significant differences between the 2 groups in terms of the surgical parameters, the postoperative outcome, or the extent of resection. No cases of liver failure, infarction, abscess or biliary fistula were found in group 1. The extent of resection and the histological feature of the 2 groups are provided in table 3 and show that the $\mathrm{R} 0$ rates were similar in the 2 groups $(p=0.731)$ 


\section{Long-term survival}

The mean global follow-up was $36 \pm 36$ months. The OS and DFS of the entire studied population are shown in figures $3 \mathrm{~A}$ and $3 \mathrm{~B}$, respectively. The overall median survival time was 21.8 months in group 1 and 23.6 months in group 2, without significant intergroup differences $(p=0.843)$. The median DFS was 11.2 in group 1 and 13.3 months in group 2 $(p=0.832)$. 


\section{DISCUSSION}

While several studies have examined the prognostic value of clinical and histological factors, including age, BMl, lymph node invasion, and margin thickness, few have evaluated the impact of anatomical variations, such as the presence of ARHA on the postoperative course of $\mathrm{PD}(10-13)$. This matched case-controlled study showed that the presence of an ARHA did not impact the perioperative complications or the oncological prognosis.

Although special attention was paid to determine the presence of an ARHA during preoperative explorations, a high percentage of ARHA was ignored until surgery. Indeed, about one-third of ARHAs were discovered perioperatively, a feature that has been described previously (12). Stauffer et al. reported a rate of preoperatively unknown ARHA of $64 \%(11)$. This finding emphasizes the need for standardization of imaging reports that mention the presence or absence of arterial anatomical variations prior to PD. This knowledge may allow for preoperative embolization to avoid perioperative hemorrhagic complications. Preoperative embolization favors the development of arterial collaterals to the liver, including the opening of intrahepatic shunts, which may prevent the risk of liver failure when an ARHA must be sacrificed (16). We never opted for this procedure which probably doesn't decrease the risk of biliary anastomotic fistula. When an ARHA appears to be invaded preoperatively, neoadjuvant chemo-radiotherapy may be indicated to reduce the rate of incomplete resection with arterial preservation (12). To bridge the lack of relevance of imaging results, we suggest that all PD begin through a SMA right first approach with dissection to free the first 3 centimeters, where AHRAs mostly arise $(17 ; 18)$. From an oncological point of view, the SMA first approach (a right-to-left early retropancreatic dissection) may reduce the rate of an $\mathrm{R} 1$ or $\mathrm{R} 2$ resection.

This study also provided information regarding the management of ARHAs in patients with cancer of the pancreatic head. Although one-fifth of AHRAs crossed through the tumor, the vessel could be preserved in most cases, an observation that is in line with previous reports 
$(13 ; 19)$ and which could explain the lack of significant differences between the 2 groups in our study.

In our series, 4 small caliber ARHA were sacrificed without relevant postoperative consequences. Unfortunately, we have little information about the decision to sacrifice or reconstruct the ARHA, especially concerning the back-flow from the distal part in the cases where arteries were sacrificed. To date, no report about the cut-off caliber from which ARHA might be repaired has been published. When the main hepatic artery arises from the SMA (type 9 of Michel's classification), it must be repaired (17). We learned from liver transplantation techniques that when an ARHA reconstruction is necessary, the easiest way to do so is to bridge the ARHA in the stump of the gastro-duodenal artery (GDA). After PD, the GDA stump is frequently not usable, and the ARHA can be reimplanted in the splenic artery end-to-end or end-to-side using a saphenous vein jump graft.

One bias in our study is that all PD were performed by senior surgeons with a large amount of experience in liver transplantation and a routine level of experience in arterial hepatic dissection and reconstruction, which may have reduced the postoperative morbidity and the incidence of $\mathrm{R} 1$ or $\mathrm{R} 2$ resections. Performing intraoperative liver Doppler ultrasonography is recommended to ensure the results of the arterial sacrifice or reconstruction and to prevent postoperative complications $(20 ; 21)$. We believe that surgical expertise is a key point in pancreatic surgery to reduce morbidity and improve survival, and these patients should be managed in high-volume centers $(1 ; 2 ; 22)$.

In conclusion, this matched case-controlled study showed that the presence of an AHRA during PD for malignant disease was not associated with an increased rate of postoperative complications or reduced OS or DFS. Patients requiring PD should be referred to upper GI surgical centers where digestive arterial reconstructions are routinely performed. This improves the safety of complex pancreatic surgery without jeopardizing the oncological prognosis. 



\section{REFERENCES}

(1) van Heek NT, Kuhlmann KF, Scholten RJ, de Castro SM, Busch OR, van Gulik TM, et al. Hospital volume and mortality after pancreatic resection: a systematic review and an evaluation of intervention in the Netherlands. Ann Surg 2005 Dec;242(6):781-8, discussion.

(2) Begg CB, Cramer LD, Hoskins WJ, Brennan MF. Impact of hospital volume on operative mortality for major cancer surgery. JAMA 1998 Nov 25;280(20):1747-51.

(3) Lin HC, Xirasagar S, Lee HC, Chai CY. Hospital volume and inpatient mortality after cancerrelated gastrointestinal resections: the experience of an Asian country. Ann Surg Oncol 2006 Sep;13(9):1182-8.

(4) Rayar M, Sulpice L, Meunier B, Boudjema K. Enteral nutrition reduces delayed gastric emptying after standard pancreaticoduodenectomy with child reconstruction. J Gastrointest Surg 2012 May;16(5):1004-11.

(5) Sulpice L, Rayar M, D'Halluin PN, Harnoy Y, Merdrignac A, Bretagne JF, et al. Impact of age over 75 years on outcomes after pancreaticoduodenectomy. J Surg Res 2012 Nov;178(1):181-7.

(6) Cameron JL, Riall TS, Coleman J, Belcher KA. One thousand consecutive pancreaticoduodenectomies. Ann Surg 2006 Jul;244(1):10-5.

(7) Michels NA. Newer anatomy of the liver and its variant blood supply and collateral circulation. Am J Surg 1966 Sep;112(3):337-47.

(8) Hiatt JR, Gabbay J, Busuttil RW. Surgical anatomy of the hepatic arteries in 1000 cases. Ann Surg 1994 Jul;220(1):50-2.

(9) Rong GH, Sindelar WF. Aberrant peripancreatic arterial anatomy. Considerations in performing pancreatectomy for malignant neoplasms. Am Surg 1987 Dec;53(12):726-9.

(10) Jah A, Jamieson N, Huguet E, Praseedom R. The implications of the presence of an aberrant right hepatic artery in patients undergoing a pancreaticoduodenectomy. Surg Today 2009;39(8):669-74.

(11) Stauffer JA, Bridges MD, Turan N, Nguyen JH, Martin JK. Aberrant right hepatic arterial anatomy and pancreaticoduodenectomy: recognition, prevalence and management. HPB (Oxford) 2009 Mar;11(2):161-5.

(12) Turrini O, Wiebke EA, Delpero JR, Viret F, Lillemoe KD, Schmidt CM. Preservation of replaced or accessory right hepatic artery during pancreaticoduodenectomy for adenocarcinoma: impact on margin status and survival. J Gastrointest Surg 2010 Nov;14(11):1813-9.

(13) Eshuis WJ, Olde Loohuis KM, Busch OR, van Gulik TM, Gouma DJ. Influence of aberrant right hepatic artery on perioperative course and longterm survival after pancreatoduodenectomy. HPB (Oxford) 2011 Mar;13(3):161-7.

(14) Bassi C, Dervenis C, Butturini G, Fingerhut A, Yeo C, Izbicki J, et al. Postoperative pancreatic fistula: an international study group (ISGPF) definition. Surgery 2005 Jul;138(1):8-13. 
(15) Wente MN, Bassi C, Dervenis C, Fingerhut A, Gouma DJ, Izbicki JR, et al. Delayed gastric emptying (DGE) after pancreatic surgery: a suggested definition by the International Study Group of Pancreatic Surgery (ISGPS). Surgery 2007 Nov;142(5):761-8.

(16) Miyamoto N, Kodama Y, Endo H, Shimizu T, Miyasaka K, Tanaka E, et al. Embolization of the replaced common hepatic artery before surgery for pancreatic head cancer: report of a case. Surg Today 2004;34(7):619-22.

(17) Varty PP, Yamamoto H, Farges O, Belghiti J, Sauvanet A. Early retropancreatic dissection during pancreaticoduodenectomy. Am J Surg 2005 Apr;189(4):488-91.

(18) Dumitrascu T, David L, Popescu I. Posterior versus standard approach in pancreatoduodenectomy: a case-match study. Langenbecks Arch Surg 2010 Aug;395(6):67784.

(19) Lee JM, Lee YJ, Kim CW, Moon KM, Kim MW. Clinical implications of an aberrant right hepatic artery in patients undergoing pancreaticoduodenectomy. World J Surg 2009 Aug;33(8):1727-32.

(20) Yamamoto S, Kubota K, Rokkaku K, Nemoto T, Sakuma A. Disposal of replaced common hepatic artery coursing within the pancreas during pancreatoduodenectomy: report of a case. Surg Today 2005;35(11):984-7.

(21) Shukla PJ, Barreto SG, Kulkarni A, Nagarajan G, Fingerhut A. Vascular anomalies encountered during pancreatoduodenectomy: do they influence outcomes? Ann Surg Oncol 2010 Jan;17(1):186-93.

(22) Kennedy TJ, Cassera MA, Wolf R, Swanstrom LL, Hansen PD. Surgeon volume versus morbidity and cost in patients undergoing pancreaticoduodenectomy in an academic community medical center. J Gastrointest Surg 2010 Dec;14(12):1990-6. 


\section{LEGENDS to Tables and Figures}

Table 1. Demographic data and histopathological features of the two matching groups

Table 2. Surgical data and postoperative complications according to the presence of ARHAs

Table 3. Extent of resection and histological features in patients with or without ARHAs

Figure 1. Type-3 ARHA by Michels classification (replaced RHA). 1A. Enhanced axial CT-scan showing an AHRA (white arrow). 1B. Enhanced angio-MRI showing AHRA (white arrow). 1C. Intraoperative picture showing a preserved type-3 AHRA (white arrow) and SMA (black arrow).

Figure 2. Diagram chart

Figure 3. Survival according to the presence (group 1) or absence (group 2) of an ARHA. 3A Overall survival, log-rank test, $P=0.843$; 3B Disease-free survival, log-rank test, $P=0.832$ 
Table 1. Demographic data and histopathological features of the two matching groups

\begin{tabular}{lccc} 
Variable & $\begin{array}{c}\text { Group 1 } \\
\text { AHRA } \\
\mathrm{n}(\%)\end{array}$ & $\begin{array}{c}\text { Group 2 } \\
\text { no AHRA }\end{array}$ & p \\
& 29 & $\mathrm{n}(\%)$ & \\
\hline $\begin{array}{l}\text { Number } \\
\text { Sex }\end{array}$ & & 55 & 0.861 \\
$\quad$ male & $16(55)$ & $30(55)$ & \\
$\quad 13(45)$ & $25(45)$ & \\
female & $62.9 \pm 12$ & $62.5 \pm 11$ & 0.861 \\
Body mass index* & $24.5 \pm 4$ & $24.4 \pm 4$ & 0.921 \\
Type of tumor & & & 0.975 \\
pancreatic adenocarcinoma & 19 & 38 & \\
malignant ampulloma & 3 & 6 & \\
cholangiocarcinoma & 5 & 7 & \\
endocrine tumor & 2 & 4 & \\
Lymph node status $(\mathrm{N}+)$ & $16(55)$ & $26(47)$ & 0.646 \\
\hline
\end{tabular}


Table 2. Surgical data and postoperative complications according to the presence of an ARHA

\begin{tabular}{lccc} 
Variable & $\begin{array}{c}\text { Group 1 } \\
\text { AHRA } \\
\mathrm{n}(\%)\end{array}$ & $\begin{array}{c}\text { Group 2 } \\
\text { no AHRA }\end{array}$ & p \\
& 29 & $55(\%)$ & \\
\hline Number & & & \\
\hline & & & \\
Surgical procedure parameters & $334.5 \pm 83$ & $341 \pm 106$ & 0.984 \\
operative time (min)* & $4(14)$ & $16(29)$ & 0.195 \\
vein resection & $3(10)$ & $4(7)$ & 0.688 \\
adjacent organ resection & $15(51)$ & $30(55)$ & 0.987 \\
pancreatic duct stenting & $18(62)$ & $29(53)$ & 0.556 \\
intraoperative blood infusion & & & \\
& & & \\
Postoperative parameters & $17.2 \pm 8$ & $20.7 \pm 13$ & 0.314 \\
length of hospital stay (days)* & $10(34)$ & $24(44)$ & 0.562 \\
delayed gastric emptying & $5(17)$ & $13(24)$ & \\
$\quad$ grade B & $5(17)$ & $11(20)$ & \\
$\quad$ grade C & $3(10)$ & $9(16)$ & 0.531 \\
pancreatic fistula & $0(0)$ & $0(0)$ & \\
$\quad$ grade A & $2(7)$ & $5(9)$ & \\
grade B & $1(3)$ & $4(7)$ & \\
grade C & $4(14)$ & $9(16)$ & 1 \\
postoperative hemorrhage & $0(0)$ & $21(4)$ & 0.542 \\
biliary fistula & $7(24)$ & $32(58)$ & 0.292 \\
systemic infection & $8(28)$ & 0.524 \\
surgical revision & $14(48)$ & 0.411 \\
morbidity & $3(10)$ & & \\
postoperative mortality & & & \\
\hline
\end{tabular}


Table 3: Extent of resection and histological features after resection in patients with or without ARHAs

\begin{tabular}{lccc} 
Variable & $\begin{array}{c}\text { Group 1 } \\
\text { AHRA } \\
\mathrm{n}(\%)\end{array}$ & $\begin{array}{c}\text { Group 2 } \\
\text { no AHRA } \\
\mathrm{n}(\%)\end{array}$ & p \\
\hline Number & 29 & 55 & \\
\hline & & & \\
R0 resection & $25(86)$ & $49(89)$ & 0.731 \\
lymph Nodes status (N+) & $16(55)$ & $26(47)$ & 0.646 \\
vascular embolization & $8(28)$ & $10(18)$ & 0.472 \\
perineural infiltration & $13(45)$ & $25(45)$ & 0.861 \\
\hline
\end{tabular}


Figure 1.


Figure 1. Type-3 ARHA by Michels classification (replaced RHA). 1A. Enhanced axial CT-scan showing an AHRA (white arrow). 1B. Enhanced angio-MRI showing an AHRA (white arrow). 1C. Intraoperative picture showing a preserved type-3 AHRA (white arrow) and SMA (black arrow). 
Figure 2. Diagram chart
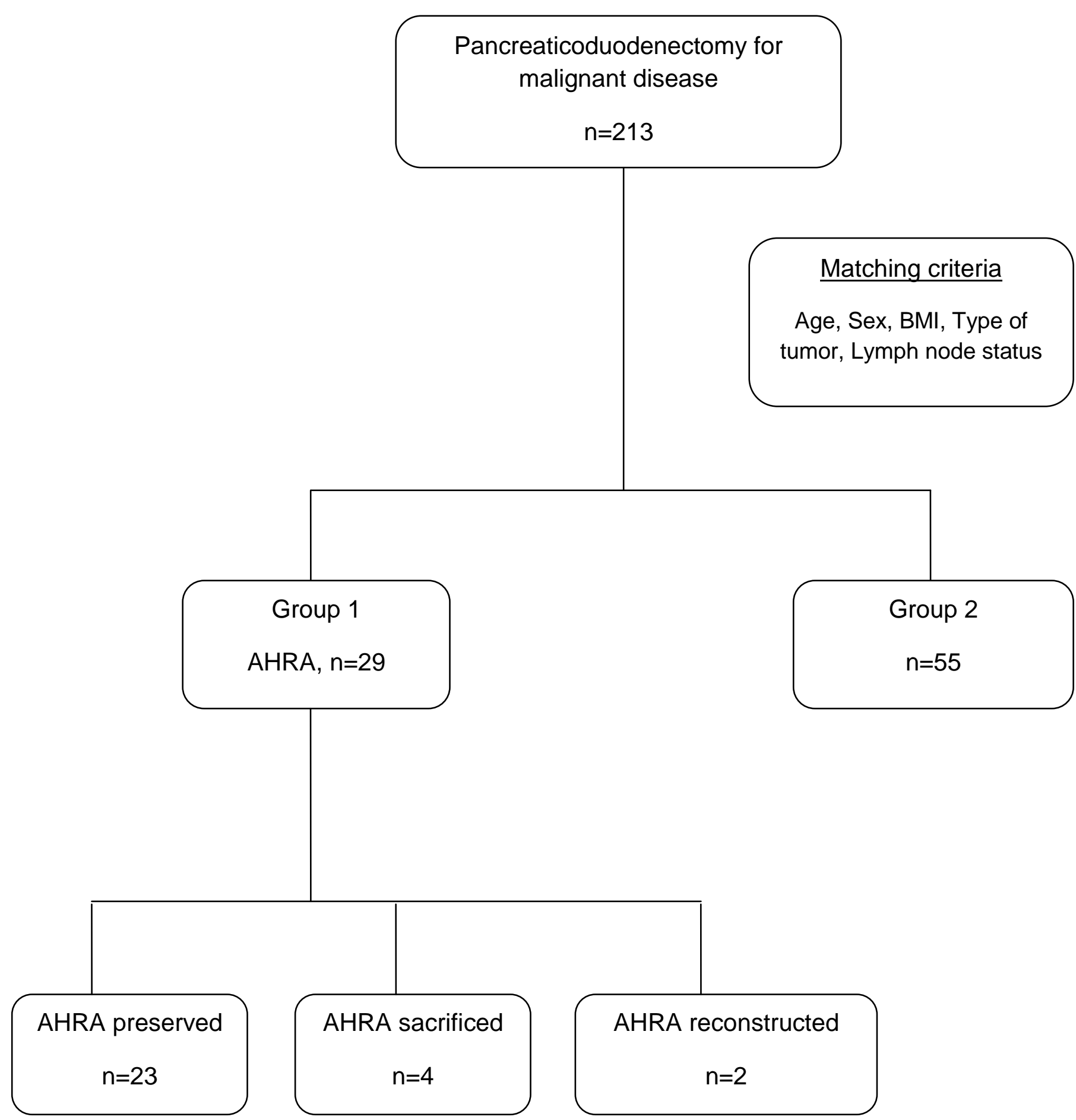
Figure 3A.

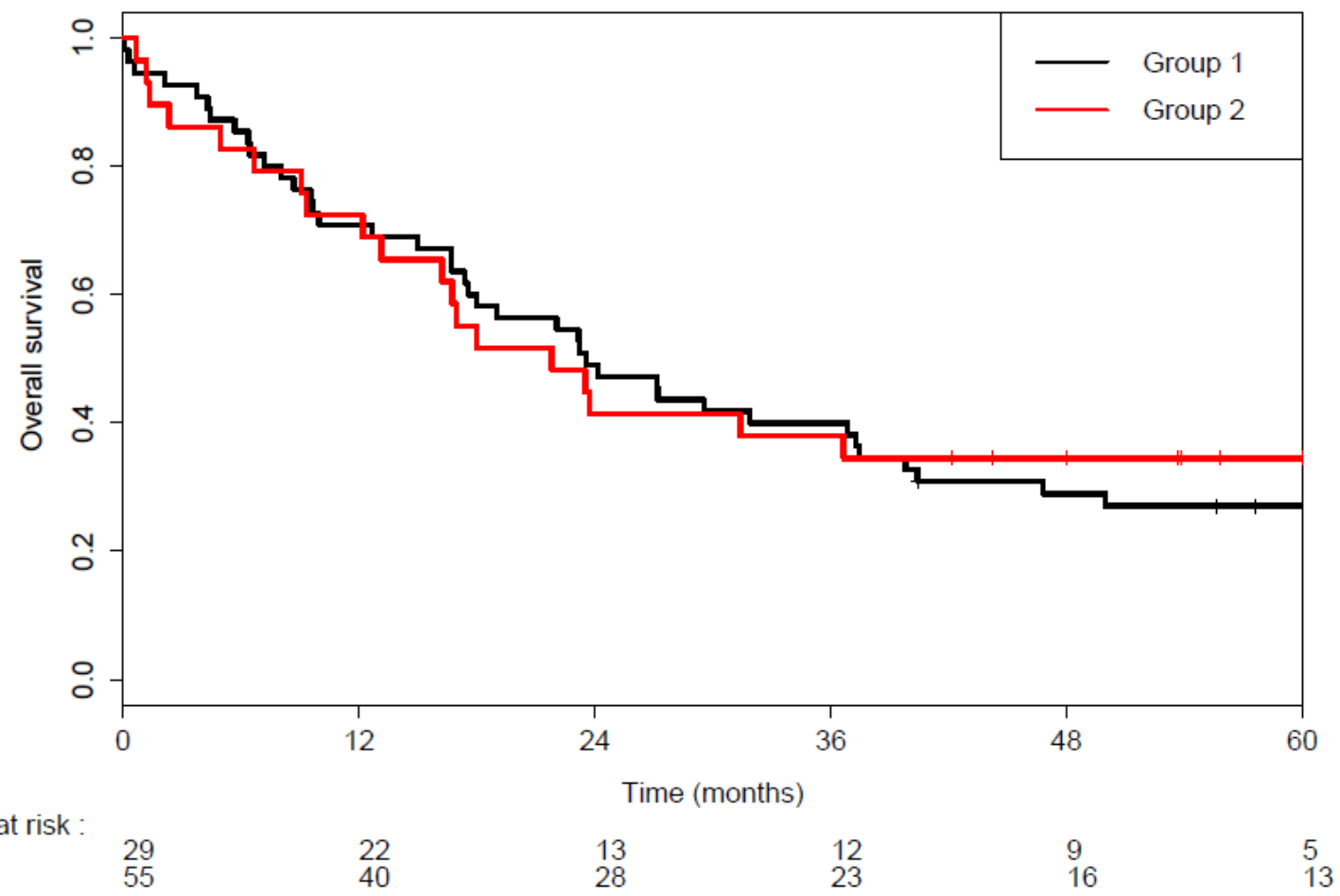

Overall survival according to the presence (group 1) or absence (group 2) of ARHAs. Log-rank test, $P=0.843$ 
Figure 3B.

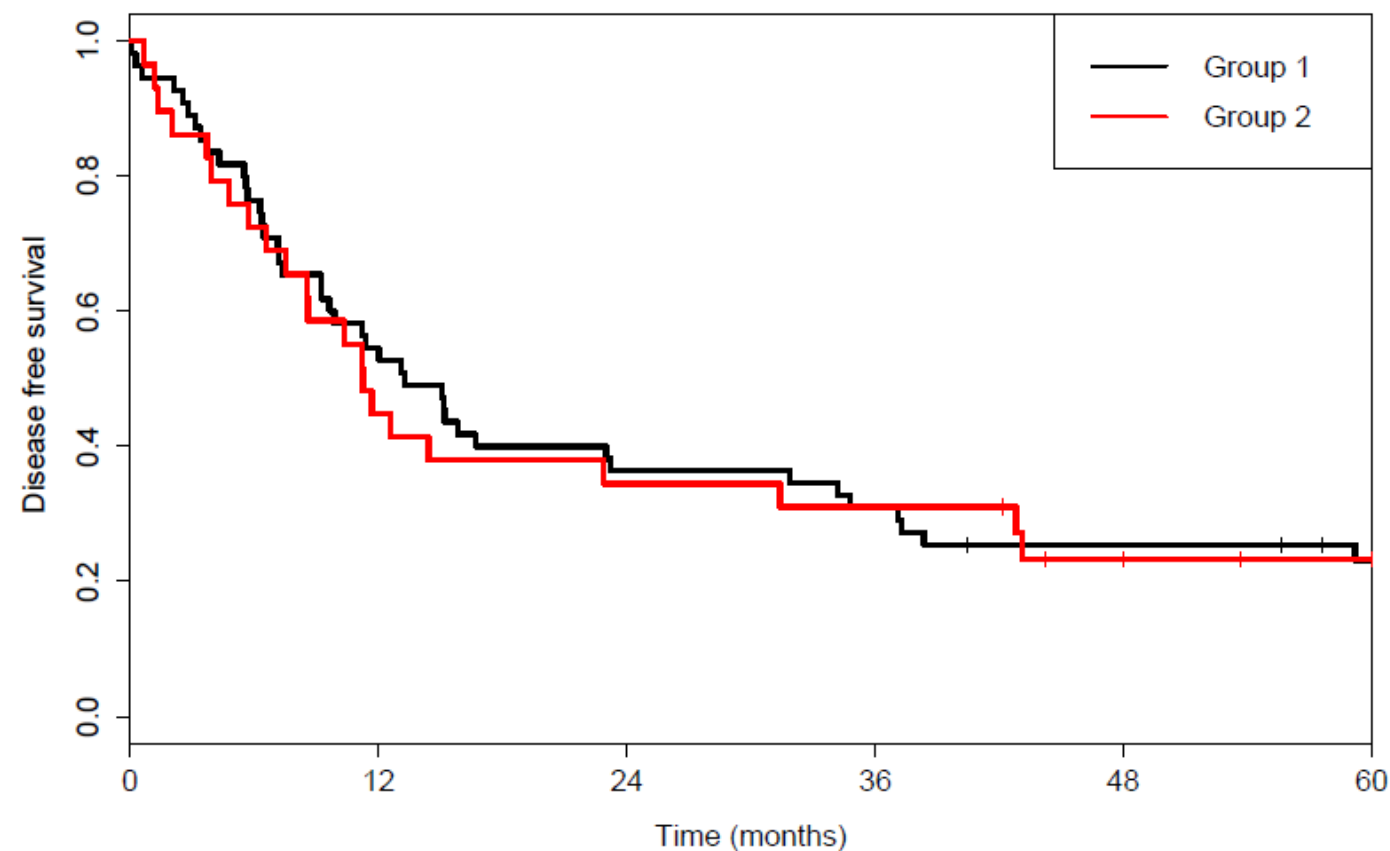

patients at risk :

group 1

$\begin{array}{ll}29 & 14 \\ 55 & 31\end{array}$

11
21

10
18

6
14

Disease-free survival according to the presence (group 1) or absence (group 2) of ARHAs. Log-rank test, $P=0.832$ 